\title{
INTERNAL FIXATION IN THE TREATMENT OF FRACTURES OF THE SHAFTS OF THE RADIUS AND ULNA IN ADULTS
}

\author{
The Value of Delayed Operation in the Prevention of Non-union
}

\author{
J. E. M. Smith, Stoke-on-Trent, England
}

Formerly of the Birmingham Accident Hospital

Fractures of the shafts of the radius and ulna require more accurate reduction than do fractures of the shafts of other long bones, because malunion in these injuries may result in serious loss of pronation and supination. Although some of these fractures can be treated conservatively, others are encountered in which closed treatment fails and open reduction and internal fixation are required.

\section{LIMITATIONS OF CONSERVATIVE TREATMENT}

A good reduction may not be obtained or may be lost when the initial swelling subsides. Union of these fractures is often slow and a period of four or five months in plaster is often necessary. There is with conservative, as with operative, treatment a definite incidence of non-union, which with conservative treatment is about 6 per cent. When union is slow a gradual deterioration in position can occur over a period of weeks or months, sometimes necessitating a late operation which can be difficult and unsatisfactory. Despite these limitations, conservative treatment is the method of choice for patients in whom reduction can be obtained and maintained.

It is undesirable to compare the results of conservative with those of operative treatment because the latter should generally be used only for fractures not suitable for conservative measures, or when those measures have failed. Precise indications for operation cannot easily be laid down and may be misleading. The surgeon who is not prepared to make full use of both methods cannot give of his best in the treatment of these difficult fractures.

The principles of conservative treatment were well described by Evans in 1951. This paper will in some ways be complementary to that report because it describes the experience gained in a series of forearm fractures treated by internal fixation.

\section{MATERIAL}

The present review covers seven years from 1950 to 1956 , during which 112 adults with fractures of the shafts of the radius and ulna were treated by open reduction and internal fixation. The term " adult" is used to include those in whom the epiphyses had either fused or were about to fuse; a few children who required internal fixation are excluded from this

TABLE I

The Cause of 130 Fractures Treated by Operation in 102 Patients

\begin{tabular}{lll}
\hline Traffic'accidents 46 & Falls $37 \quad$ Industrial accidents 19
\end{tabular}

study. In ten patients who could not be traced there was insufficient information for assessment, leaving 102 patients with a total of 130 fractures treated by internal fixation. Fractures very close to the joints-that is, the uppermost and lowermost fifths of the bones-are also excluded from this review. All patients were kept under observation for at least a year. In assessing the time required to obtain union, only radiological evidence was used because clinical 
impressions are sometimes misleading. Most of the patients had been radiographed at approximately monthly intervals until union was obtained, and this made accurate assessment of the time to union relatively easy.

The 112 patients represent the collective material of six surgeons working in busy fracture units. In seven years, therefore, each surgeon on the average encountered less than twenty patients requiring internal fixation for these fractures-about three patients a year. Normally extensive personal experience is, therefore, not gained rapidly.

The causative violence is shown in Table I. Whereas traffic accidents and falls caused the largest number of injuries, some of the most severe were from accidents with industrial or agricultural machinery. There were seventy men and thirty-two women.

The patients' ages are shown in Figure 1. The large number of fractures occurring between the ages of twenty and twenty-nine is due to the frequency of motor cycle accidents.

Seventeen of the injuries were compound, eight with serious wounds and severe soft-tissue damage, and nine with puncture wounds.

The anatomical varieties of fracture are shown in Table II. Most of those requiring operation were fractures at the junction of the middle and lowermost thirds of the radius with inferior radio-ulnar subluxation or dislocation.

TABLE II

ANATOMICAL VARIETIES OF INJURY

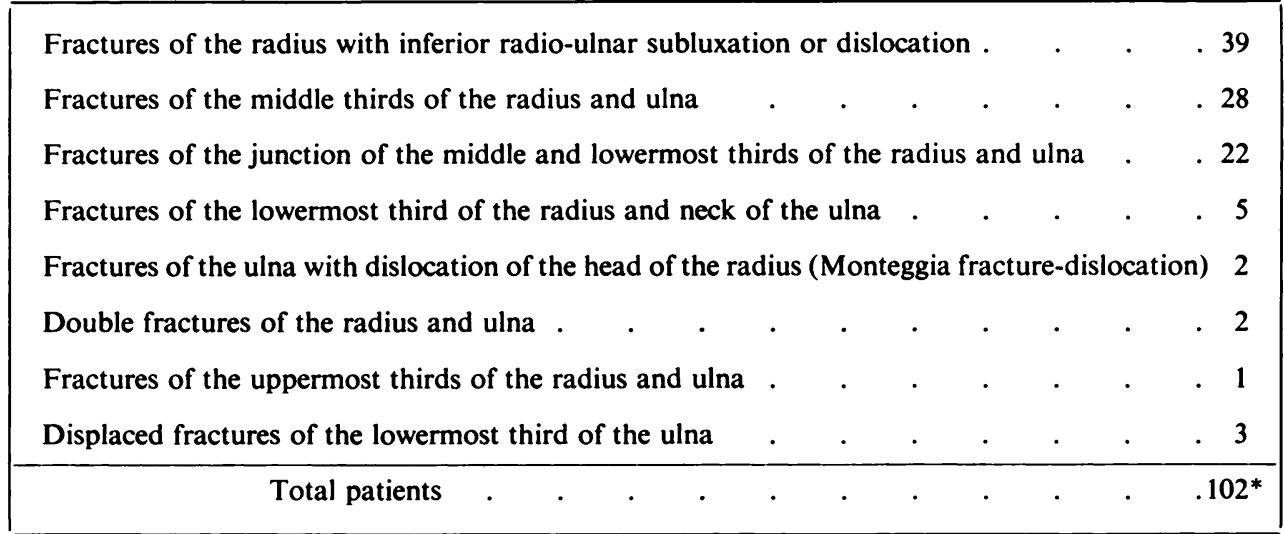

* Four of these patients had associated fractures of the shaft of the humerus and two patients had dislocations of the elbow in addition to the two patients with the Monteggia fractures.

\section{METHOD OF INTERNAL FIXATION}

The most satisfactory fixation was that obtained from well applied metal plates and screws. Experience with medullary nailing has been small and not very favourable. The nail is sometimes difficult to insert in the radius because of the curve of the bone, and it seldom prevents rotatory movement of the fractured ends. The method is sometimes of value in the treatment of certain severe compound injuries with skin loss.

Cerclage wires, Kirschner wires and other precarious methods of fixation are not usually satisfactory and are sometimes harmful.

Primary autogenous bone grafting was done in a few patients. The use of large tibial grafts greatly increases the extent of the operation, and is not justifiable as a primary measure. Union is not necessarily more rapid than after accurate plating.

In fractures in which there is displacement and overlap of both bones, it is usually advisable to plate both radius and ulna.

VOL. $41 \mathrm{~B}$, NO. 1, feBrUARY 1959 
Severity of injury-As might be expected, union was in general slower after the more severe injuries. Of the seventeen compound fractures, some of which were very severe, six went on to non-union or required bone grafting.

Site of fracture-Non-union was commonest in fractures of the mid-shaft and in fractures at the junction of middle and lowermost thirds, but this partly reflects the increased frequency of injury at these levels. There was no substantial difference in the incidence of non-union in the radius as compared with the ulna. The sites of thirty-one fractures with slow union or non-union are shown in Table III.

TABLE III

Sites of Thirty-one Fractures with Slow or Non-union

\begin{tabular}{|c|c|c|}
\hline Site of fracture & Radius & Ulna \\
\hline $\begin{array}{l}\text { Junction of middle and } \\
\text { uppermost third }\end{array}$ & 1 & 1 \\
\hline Middle third & 11 & 5 \\
\hline $\begin{array}{l}\text { Junction of middle and } \\
\text { lowermost third }\end{array}$ & 9 & 4 \\
\hline $\begin{array}{l}\text { Total fractures with slow } \\
\text { or non-union }\end{array}$ & 21 & 10 \\
\hline $\begin{array}{l}\text { (Total of fractures in the } \\
\text { series). }\end{array}$ & (86) & (44) \\
\hline
\end{tabular}

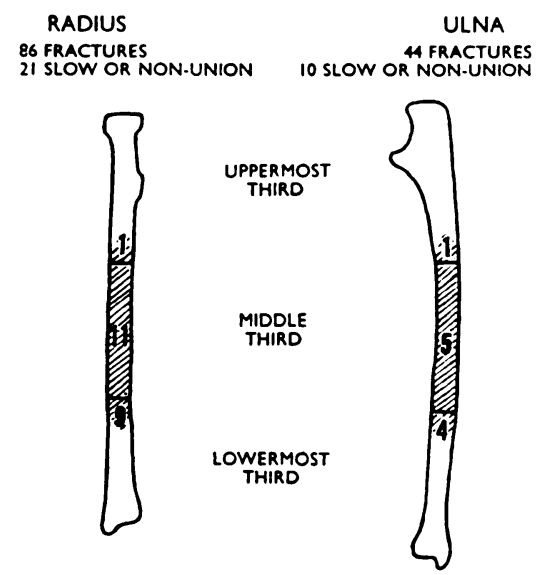

Age-Delayed union and non-union were most frequent in patients between the ages of thirty and fifty-five - the intermediate age group. It was lower in those under thirty and in those over sixty, as shown in Figure 2.

Quality of internal fixation-The quality of internal fixation was important. Several fractures developed non-union because the plate was very small or poorly applied; rigidity of internal fixation, however, bore no relation to speed of union. Union with poor fixation was often rapid, and that with good fixation often slow. Nevertheless a well applied plate can often hold a fracture for a long time in relative safety, and poor internal fixation should be avoided. Medullary nails are less satisfactory than plates. Firm fixation, though desirable, cannot always be achieved, because of comminution or proximity of the fracture to the bone end.

Plaster fixation-Some difference of opinion exists about the use of plaster after internal fixation. The results in the present series suggest that non-union is more common in fractures not treated in adequate plasters.

Ninety-three fractures had been immobilised in plaster for adequate periods, of which nine developed non-union. Of thirty-seven fractures which had either no plaster at all or plaster for short or irregular periods eight developed non-union.

While the speed of functional recovery in cases successfully treated without plaster is very striking, the higher incidence of non-union makes routine use of the method unjustifiable.

The timing of operation-Since the paper by Murray in 1941 on " The timing of the fracturehealing process" it has been widely believed that the best time to carry out internal fixation of a fracture is as soon after injury as possible. Immediate operation was believed to cause the least interference with the normal healing process. Added advantages of early operation are ease of exposure, ease of reduction and precise identification of damaged tissues unaltered by oedema and fibrosis. Most of the fractures in this series were subjected to early internal fixation.

VOL. 41 B, NO. 1, FEBRUARY 1959 
In about a third of the total number, delayed operation was carried out for one or more of the following reasons: 1) Loss of reduction after manipulation or failure to obtain reduction after repeated manipulation. 2) Patients transferred late from other hospitals. 3) Compound

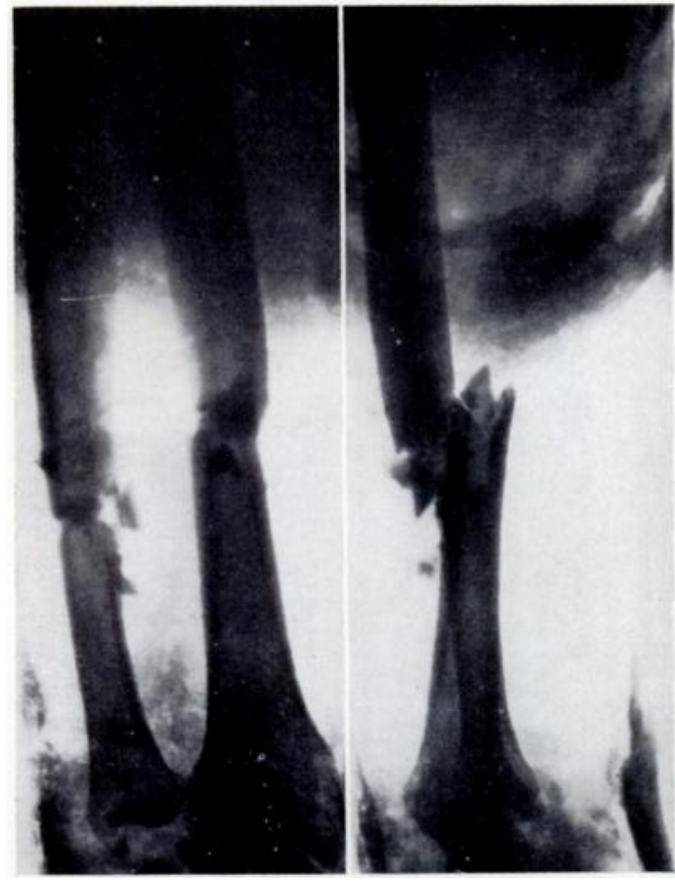

FIG. 3

A patient aged twenty-seven with a fracture of the radius and ulna which shows displacement, shortening and comminution. fractures in which operation was delayed to obtain skin healing. 4) Patients with severe associated injuries in whom treatment of the fractured forearm had to be delayed.

Fractures of the shaft of the radius and ulna in adults do not ordinarily heal with abundant callus, but it was seen that in a few fractures the rate of healing was unusually brisk, with profuse subperiosteal callus. Further investigation showed that this was usually seen in patients who had a delayed operation and was seldom seen in fractures plated in the first six days. It was then decided to review the whole series with special regard to the timing of operation, and the results in our own cases were surprising; it was found that every fracture with nonunion and most of those with slow union occurred in patients operated upon early, and in this series non-union did not occur in any patient operated upon after the sixth day. It should not be thought that all fractures treated by delayed operation showed union with abundant subperiosteal callus, for some showed no external callus at all; yet evidence of the benefits from delayed operation was strikingly shown in the final analysis when it was found that all the fifty-two fractures so treated united, fifty of them within six months of injury.

A detailed comparative analysis of patients treated by early and by delayed operation is shown in Tables IV to VIII, where it will be seen that there is no essential difference in the two groups as regards expectation of union at the time of injury.

TABLE IV

The Effect of Early and Delayed Operation on Compound Fractures OF THE FOREARM

\begin{tabular}{|ccc|}
\hline Type of fracture & Early operation & Delayed operation \\
\hline $\begin{array}{c}\text { Severe, with extensive } \\
\text { soft-tissue damage }\end{array}$ & 6 fractures & 2 fractures \\
\hline $\begin{array}{c}\text { Not severe, without } \\
\text { extensive soft-tissue } \\
\text { damage }\end{array}$ & $\frac{4}{6}$ fractures & No non-unions \\
\hline
\end{tabular}

To summarise the contents of the Tables, the adverse factors in the expectation of union are: 1) compound injuries; 2) fractures of middle and lowermost thirds of the bones; 3 ) age between thirty-five and fifty-five, at which age patients seem most prone to non-union; and 4) severe soft-tissue damage. 
TABLE V

Ages of 102 Patients with Fractures of the Forearm

Treated by Early and Delayed Operation

\begin{tabular}{|ccc|}
\hline $\begin{array}{c}\text { Age } \\
(\text { years })\end{array}$ & $\begin{array}{c}\text { Early operation } \\
(\text { patients })\end{array}$ & $\begin{array}{c}\text { Delayed operation } \\
\text { (patients })\end{array}$ \\
\hline $17-19$ & 2 & 4 \\
$20-29$ & 21 & 9 \\
$30-39$ & 14 & 7 \\
$40-49$ & 11 & 9 \\
$50-59$ & 4 & 3 \\
$60-69$ & 11 & 7 \\
\hline Total patients & 63 & 39 \\
(Total fractures) & $(78)$ & $(52)$ \\
\hline
\end{tabular}

TABLE VI

anatomical Varieties of Fractures Treated by Early and Delayed Operation

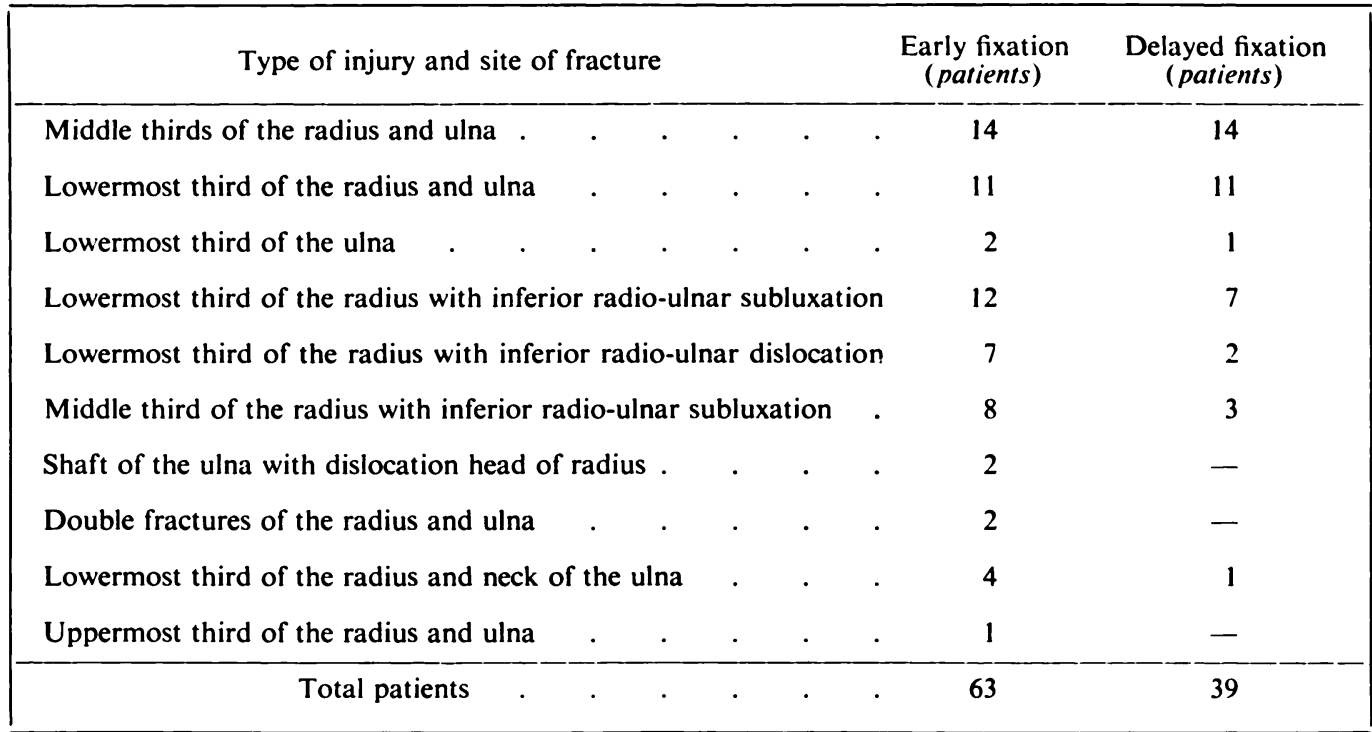

TABLE VII

Comparison of the Types of Injury Treated by Early and Delayed Operation

\begin{tabular}{|c|c|c|c|c|}
\hline \multicolumn{2}{|c|}{ Cause of fractures } & & $\begin{array}{l}\text { Early operation } \\
\quad \text { (patients) }\end{array}$ & $\begin{array}{c}\text { Delayed operation } \\
\text { (patients) }\end{array}$ \\
\hline Traffic accidents & . & . & 27 & 19 \\
\hline Falls & . & - & 24 & 13 \\
\hline Machinery accidents & . & . & 12 & 7 \\
\hline Total patients & . & & 63 & 39 \\
\hline
\end{tabular}

VOL. 41 B, NO. 1, FEBRUARY 1959 
It will be seen that all these adverse conditions are well represented proportionately in the series treated by delayed operation. Also it should be mentioned that both series had been operated upon by the same group of surgeons.

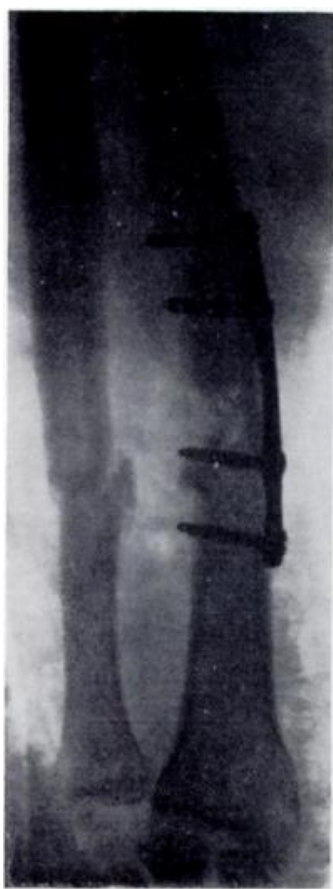

FIG. 4

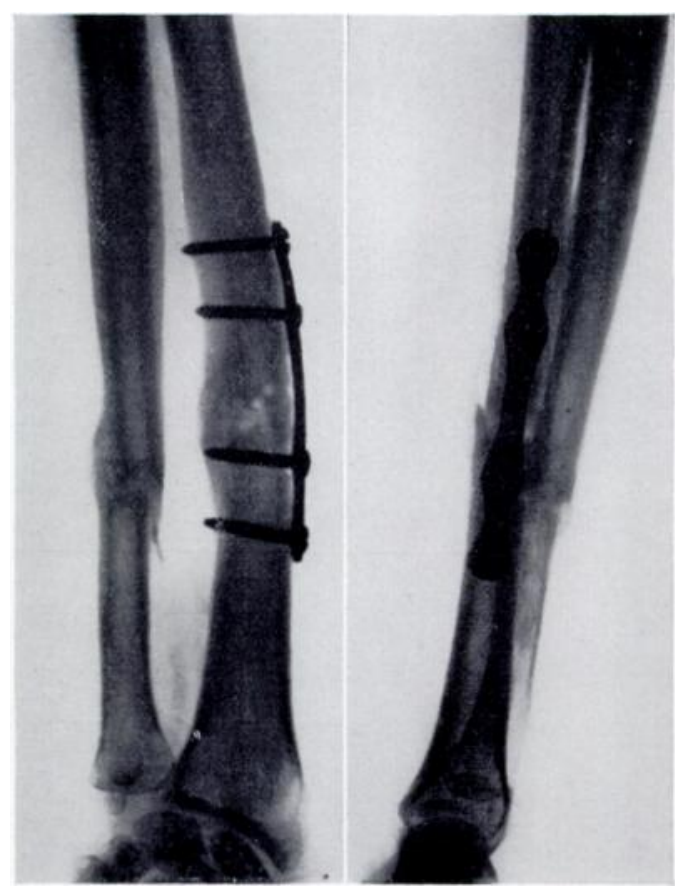

Fig. 5

Figure 4-Twenty-four days after the injury shown in Figure 3 the bone ends have been drilled at operation and the radius has been plated. Figure 5-Ten weeks after the operation union has occurred. The patient regained full function of the forearm.

\section{THE TREATMENT OF NON-UNION}

A hasty decision must not be made to reoperate on a fracture thought to have non-union, as many of these will eventually unite, however slow the initial progress has been. At the end of the third month it is common to see in the radiograph a gap between the fractured bone ends, as though the fracture had been plated in distraction; this gap is often obliterated in the next few weeks. Unless the plate and screws are very loose they should not be removed in the erroneous belief that they are holding the bone ends apart; to do this is often to invite

TABLE VIII

Summary of Results of Early and Delayed Operation

\begin{tabular}{|c|c|c|c|c|}
\hline Type of treatment & $\begin{array}{l}\text { United within } \\
6 \text { months }\end{array}$ & $\begin{array}{l}\text { United within } \\
12 \text { months }\end{array}$ & $\begin{array}{l}\text { Non-unions and } \\
\text { bone grafts }\end{array}$ & Total \\
\hline Early operation (first to sixth day). & 49 & 12 & 17 & 78 fractures \\
\hline Delayed operation (seventh day onwards) & 50 & 2 & - & 52 fractures \\
\hline
\end{tabular}

non-union. In fractures where union is very slow, well applied plates may hold them securely for several months until union occurs. Multiple operations must be avoided as the tendency to non-union is thereby increased. 
If a plate needs to be removed before radiological union is complete, bone grafting is advisable. The appearances at operation are deceptive, and bony union may be thought to be present when no more than fibrous union exists, and the removal of the plate may be followed by non-union.

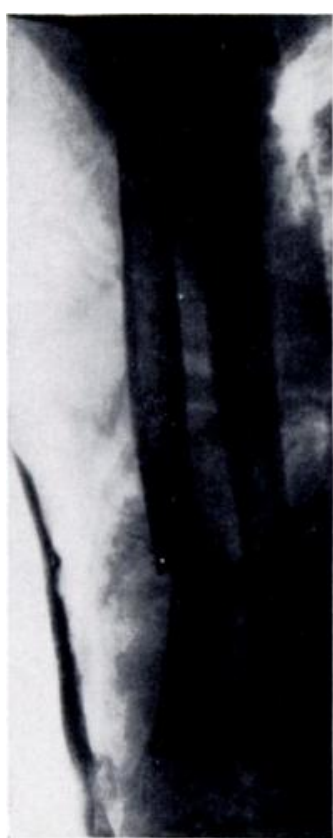

Fig. 6

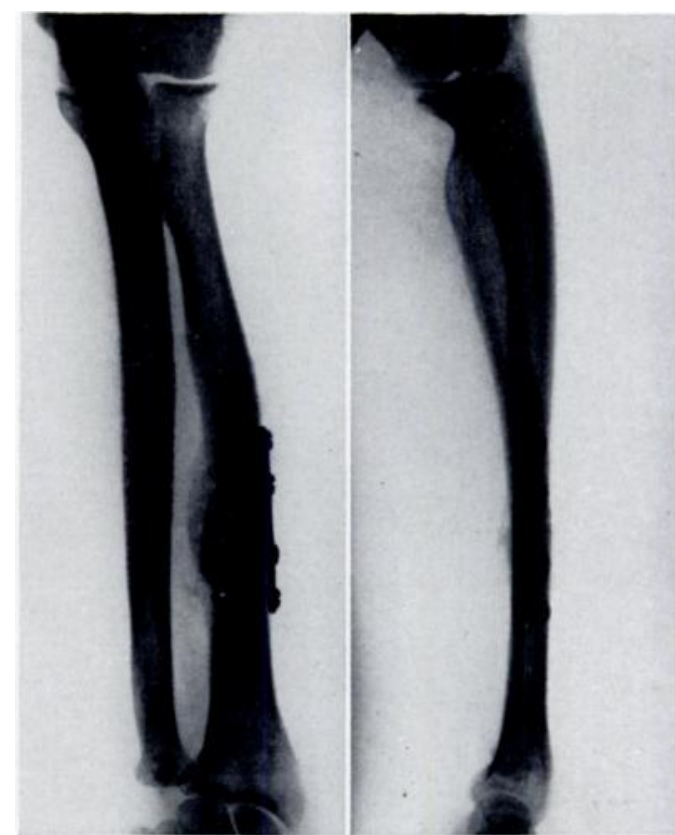

Fig. 7

Figure 6-A patient aged thirty-seven with a fracture of the radius and inferior radio-ulnar subluxation has had internal fixation performed nineteen days after the injury. Figure 7-A radiograph of the same patient thirteen weeks after the injury shows advanced union of the radius with profuse subperiosteal callus often seen after delayed operation.

When bone grafting is undertaken, a large cortical graft should be used and fixed securely to the fractured bone ends. The results of this operation in the forearm are often unsatisfactory if good fixation is not obtained. Iliac bone should be avoided as this graft is inferior to that obtained from the tibia.

TABLE IX

RESULTS OF OPERATIONS FOR NON-UNION

\begin{tabular}{|c|c|c|}
\hline & Operations & Failures \\
\hline Large tibial bone graft & 3 & No failures \\
\hline Small tibial bone graft & 3 & 2 failures \\
\hline Iliac bone graft + plate & 2 & 1 failure \\
\hline Sliding bone graft . & 2 & 2 failures \\
\hline $\begin{array}{l}\text { Removal of plate and insertion } \\
\text { of Küntscher nail . }\end{array}$ & 2 & $\begin{array}{c}1 \text { severe } \\
\text { wound infection }\end{array}$ \\
\hline Iliac bone grafts & 6 & 3 failures \\
\hline
\end{tabular}

It is unwise to excise the lower end of the ulna to promote union in the radius because this frequently causes the radius to angulate towards the ulna and increases the difficulty in obtaining union.

VOL. $41 \mathrm{~B}$, NO. 1, FEBRUARY 1959 


\section{DISCUSSION}

The most serious complication of internal fixation in the present series has been non-union. With correct timing of the operation it should be possible to reduce this to negligible proportions;

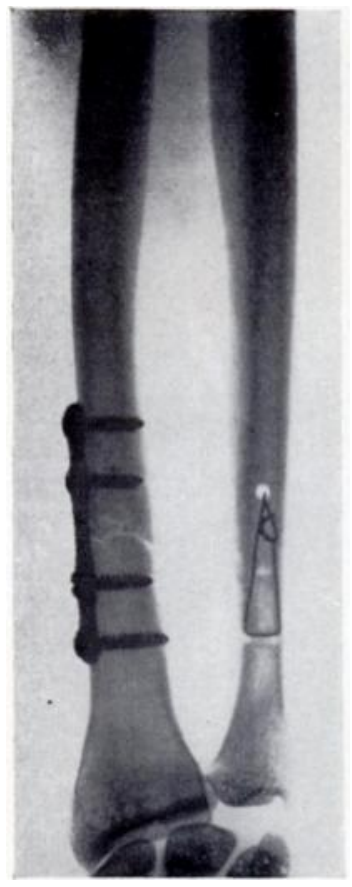

Fig. 8

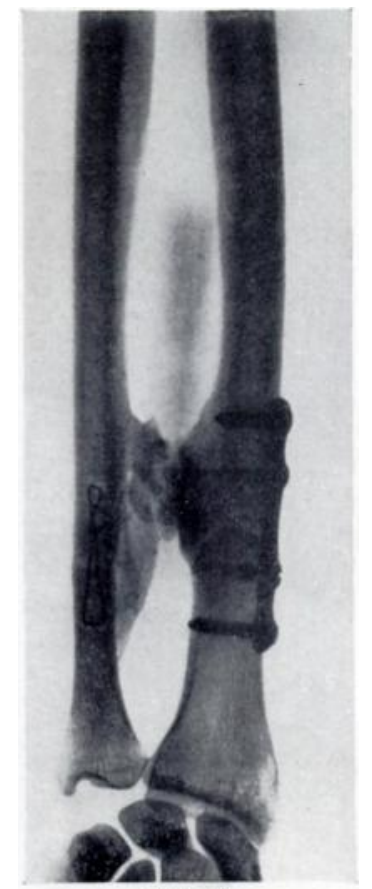

FIG. 9
FIGS. 8 AND 9

Figure 8-Internal fixation done seven days after injury in a patient aged nineteen for a fracture of the lowermost thirds of the radius and ulna with displacement and shortening. Figure 9-A radiograph of the same patient shown in Figure 8 ten weeks after the injury shows massive callus formation and cross union. This was the only patient in whom cross union occurred in the series treated by delayed operation. Later a pseudarthrosis formed in the bridge and a limited but useful range of rotation was obtained.

even so, the writer believes that there is a definite place for conservative treatment in these fractures and if reduction can be obtained and maintained without internal fixation this is the treatment of choice.

FIG. 10

Twelve weeks before this radiograph of a patient aged seventy was taken the fracture of the radius with inferior radio-ulnar subluxation was plated. There is now union with abundant subperiosteal cartilage.

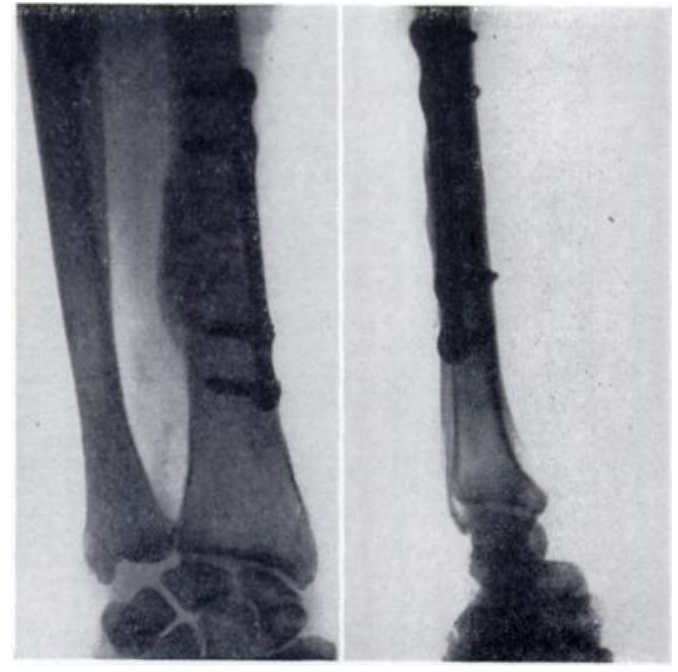

FIG. 10

Does deliberate delay greatly increase the difficulty of open reduction? In the case of the forearm it does not; a delay of seven days adds no difficulty at all, and even after a further two or three weeks the repair tissue surrounding the bone ends is still soft and easily peeled away 
from the fracture site. This repair tissue should be handled gently and never excised, because it contributes to the healing of the fracture.

The blood supply to the soft tissues surrounding these fractures is often severely damaged, and early operation does further harm to the local circulation; delay presents the advantage of allowing the local circulation to re-establish itself, with improved prospect of bone union.

In wound healing in general the cellular response appears to reach its maximum between ten and twenty days after injury, as does an open granulating surface. The timing of operation when the local cellular response is fully developed is often followed by rapid healing, as in wounds treated by secondary suture. It seems that a similar favourable repair is obtained by delayed internal fixation in the treatment of fractures.

Fig. 11

Fractures of the radius and ulna with displacement and overlap in this patient aged twenty-three were plated three weeks after injury without undue difficulty. Union occurred in five to six months by gradual obliteration of the fracture line and with minimal subperiosteal callus. This less dramatic result is often seen after delayed internal fixation.

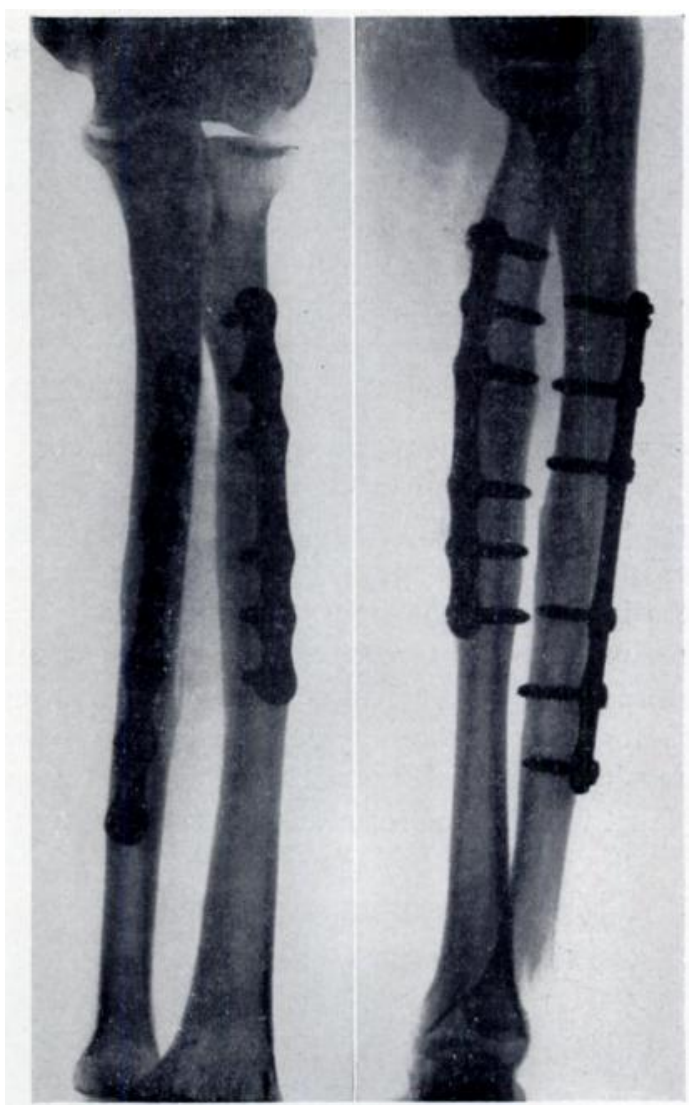

Fig. 11

\section{SUMMARY}

The place of internal fixation in the treatment of fractures of the shafts of the radius and ulna in adults is discussed, and the results in 130 fractures treated by internal fixation are reviewed.

Non-union was found to be the most frequent and serious complication after internal fixation.

The incidence of non-union can be greatly reduced if operation is delayed for at least one week, and preferably two to three weeks after injury.

Evidence is presented to support the value of delayed operation in the promotion of union of fractures.

My special thanks are due to Mr William Gissane and Mr Denys Wainwright, who have read through the paper and offered much valuable advice and helpful criticism.

I would also like to thank the surgeons of the Birmingham Accident Hospital for allowing me to review patients under their care.

\section{REFERENCES}

Evans, E. M. (1951): Fractures of the Radius and Ulna. Journal of Bone and Joint Surgery, 33-B, 548. MurRay, C. R. (1941): The Timing of the Fracture-healing Process. Its influence on the choice and application of treatment methods. Journal of Bone and Joint Surgery, 23, 598. 